\title{
Biometria de frutos e sementes e germinação de melão-de-são-caetano
}

SANTANA, S.H. ${ }^{1}$; TORRES, S.B. ${ }^{1 *}$; BENEDITO, C.P. ${ }^{1}$

Departamento de Ciências Vegetais, Universidade Federal Rural do Semi-Árido (UFERSA), Avenida Francisco Mota, 572, Costa e Silva, CEP: 59625-900, Mossoró-Brasil *sbtorres@ufersa.edu.br

\begin{abstract}
RESUMO: Objetivou-se com este trabalho fazer a caracterização biométrica de frutos e sementes de melão-de-são-caetano (Momordica charantia L.) e determinar as temperaturas cardinais para germinação das sementes desta espécie. A caracterização e a condução do experimento foram realizadas no Laboratório de Análise de Sementes da UFERSA, em MossoróRN. Os parâmetros avaliados foram: comprimento, diâmetro, número de sementes por fruto; comprimento, largura e espessura das sementes; grau de umidade, peso de mil sementes, e número de sementes por grama. Para o ensaio sobre as temperaturas, a semeadura foi realizada em caixas plásticas transparentes contendo areia esterilizada como substrato. As sementes foram incubadas nas temperaturas constantes de $10^{\circ} \mathrm{C}, 15^{\circ} \mathrm{C}, 20^{\circ} \mathrm{C}, 25^{\circ} \mathrm{C}, 30^{\circ} \mathrm{C}, 35^{\circ} \mathrm{C} \mathrm{e} 40^{\circ} \mathrm{C}$, com fotoperíodo de 8 horas. $O$ delineamento experimental foi inteiramente casualizado com quatro repetições de 50 sementes. Os frutos apresentam cerca de 49,8 $\mathrm{mm}$ de comprimento, $19,89 \mathrm{~mm}$ de diâmetro, contendo em torno de 18 sementes. As dimensões médias das sementes são: $8,9 \mathrm{~mm}$ de comprimento, $4,30 \mathrm{~mm}$ de largura, e 2,65mm de espessura. A germinação ocorre na faixa de 20 a $35^{\circ} \mathrm{C}$, porém as temperaturas ótimas para germinação de sementes de melão-de-são-caetano variam entre 25 e $30^{\circ} \mathrm{C}$.
\end{abstract}

Palavras-chave: Momordica charantia, temperatura, planta medicinal

ABSTRACT: Biometrics of fruits and seeds and germination of balsam pear. The aims of this study were to perform the biometric characterization of fruits and seeds of balsam pear (Momordica charantia L.) and to determine the cardinal temperatures for seed germination in this species. The characterization and the experiment were conducted at the Laboratory of Seed Analysis of UFERSA in Mossoró-RN. The evaluated parameters were: length, width and thickness of seeds; moisture content; one thousand seed weight; and number of seeds per gram. For the temperature assay, sowing was done in transparent plastic boxes containing sterilized sand as substrate. The seeds were then incubated at the constant temperatures of $10^{\circ} \mathrm{C}, 15^{\circ} \mathrm{C}, 20^{\circ} \mathrm{C}$, $25^{\circ} \mathrm{C}, 30^{\circ} \mathrm{C}, 35^{\circ} \mathrm{C}$ and $40^{\circ} \mathrm{C}$, with 8-hour photoperiod. Experimental design was completely randomized with four replicates of 50 seeds. Fruits have about $49.8 \mathrm{~mm}$ length and $19.89 \mathrm{~mm}$ diameter, containing around 18 seeds. The medium dimensions of seeds are: $8.9 \mathrm{~mm}$ length, $4.30 \mathrm{~mm}$ width and $2.65 \mathrm{~mm}$ thickness. There is germination in the range from 20 to $35^{\circ} \mathrm{C}$, but the optimal temperatures for the germination of balsam pear seeds vary between 25 and $30^{\circ} \mathrm{C}$.

Key words: Momordica charantia, temperature, medicinal plant

\section{INTRODUÇÃO}

O melão-de-são-caetano (Momordica charantia L.), da família Cucurbitaceae, é uma espécie pantropical, trepadeira, originária, provavelmente, do leste indiano e sul da China, monóica, raramente hermafrodita com flores amarelas solitárias nas axilas das folhas (Robinson \& Decker-Walters, 1997). É uma espécie vegetal silvestre, sendo conhecida e utilizada por suas propriedades medicinais (Grover \& Yadav, 2004; Assubaie, 2004) e ocorre em todas as regiões habitadas do país (Lorenzi, 2008).

A biometria dos frutos constitui um instrumento importante para detectar a variabilidade genética dentro de populações de uma mesma espécie, e as relações entre esta variabilidade e os fatores ambientais, fornecendo importantes informações para a caracterização dos aspectos ecológicos como o tipo de dispersão, agentes dispersores e estabelecimento das plântulas (Cruz et 
al., 2001; Alves et al., 2007). Já a caracterização das sementes está relacionada com as características de dispersão e com o estabelecimento de plântulas, sendo um subsídio importante na avaliação de tamanhos ou pesos, constituindo-se em uma estratégia que pode ser adotada para uniformizar a emergência das plântulas e para a obtenção de mudas de tamanho semelhante ou de maior vigor (Carvalho \& Nakagawa, 2000).

Estudos sobre a influência da temperatura na germinação das sementes são essenciais para entender os aspectos ecofisiológicos e bioquímicos desse processo (Bewley \& Black 1994). Para muitas espécies, a temperatura também desempenha papel fundamental na regulação da germinação. Por exemplo, sementes de certas plantas não germinam durante o inverno, apenas no verão (Gurevitch et al., 2002). A temperatura influencia o percentual de sementes germinadas, a velocidade e uniformidade de germinação (Carvalho \& Nakagawa, 2000). Além disso, a germinação ocorre dentro de certos limites, nos quais podem ser identificados três pontos críticos (temperaturas cardinais). As temperaturas máxima e mínima são os pontos críticos superior e inferior a partir dos quais as sementes não germinam. A temperatura ótima é aquela onde ocorre o maior percentual da germinação no menor tempo (Floss, 2004). Observa-se, portanto, que a temperatura é fator limitante para germinação e, sua influência varia conforme a espécie, podendo induzir a germinação de sementes que apresentam dormência (Albuquerque et al., 2003).

O presente trabalho teve como objetivo avaliar as características biométricas de frutos $\mathrm{e}$ sementes de melão-de-são-caetano e determinar as temperaturas cardinais para germinação das sementes desta espécie.

\section{MATERIAL E MÉTODO}

Coletaram-se frutos maduros de melão-desão-caetano, em outubro de 2010 nos arredores do campus da Universidade Federal Rural do Semi-Árido, em Mossoró, RN (latitude 503'40"S, longitude $37^{\circ} 23^{\prime} 51^{\prime \prime} W$ e altitude de $72 \mathrm{~m}$ ). De acordo com a classificação de Köppen, o clima na região é do tipo BSwh', isto é, seco, muito quente e com estação chuvosa no verão (Carmo Filho \& Oliveira, 1995).

A coleta e preparo das sementes foi feita manualmente, retirando-se a mucilagem em água corrente e seguida de secagem a sombra $\left(30-35^{\circ} \mathrm{C}\right.$; $60 \%$ UR), por 72 horas, em ambiente natural e sobre papel toalha. Após a secagem, as sementes foram embaladas em saco de papel Kraft e armazenadas, por aproximadamente um ano, em ambiente com temperatura controlada de $16-18^{\circ} \mathrm{C}$ e umidade relativa de $50-55 \%$, até a realização do presente estudo.

O comprimento, a largura e a espessura dos frutos e das sementes foram determinados com auxílio de um paquímetro digital com precisão de 0,05 $\mathrm{mm}$, utilizando-se 15 frutos fechados, totalizando em 250 sementes. Para cada característica, calculou-se a média, a mediana, a variância e o desvio padrão conforme Araújo Neto et al. (2002). Os dados foram classificados por meio de distribuição de frequência e plotados em histogramas de frequência (Oliveira et al., 2000).

Foi determinado, também, o peso de mil sementes, utilizando-se oito repetições de 100 sementes provenientes da porção "Semente Pura", conforme recomendações das Regras para Análise de Sementes (Brasil, 2009). Paralelamente, determinou-se o grau de umidade das sementes pelo método estufa a $105 \pm 3^{\circ} \mathrm{C}$, durante 24 horas, utilizando-se duas subamostras de $20 \mathrm{~g}$ de sementes (Brasil, 2009).

Para o estudo da germinação das sementes, utilizaram-se as temperaturas constantes de 10; $15 ; 20 ; 25 ; 30 ; 35$ e $40^{\circ} \mathrm{C}$, com fotoperíodo de oito horas. Como substrato, utilizou-se a areia lavada e esterilizada, empregando-se $197 \mathrm{~g}$ para cada caixa plástica transparente e umedecida com água destilada a $50 \%$ da capacidade de campo. Em seguida, as sementes foram semeadas entre areia com um centímetro de profundidade.

Avaliaram-se as variáveis porcentagem de germinação e tempo médio de germinação (TMG). Para germinação, utilizaram-se quatro repetições de 50 sementes onde foram feitas observações diárias, desde o início até aos 21 dias após a semeadura, quando se verificou a estabilização do processo, ou seja, o número de dias necessários para que todas as sementes germinem. Decorrido este período, contabilizou-se a porcentagem de plântulas normais (Brasil, 2009).

O tempo médio de germinação (TMG) foi realizado simultaneamente com o teste de germinação, consistindo da avaliação diária das plântulas, à mesma hora, a partir do dia em que surgiram as primeiras plântulas normais. As avaliações foram feitas até o dia da última contagem (21 dias) e para cálculo do TMG foi utilizada a metodologia proposta por (Labouriau, 1983), conforme a seguir: $t: \sum n_{i} \cdot t_{i} / \sum n$; onde: $t$ : tempo médio de germinação; $n_{\mathrm{i}}$ : número de sementes germinadas em determinado intervalo de tempo ; n: número total de sementes germinadas; $t_{i}$ : dias de germinação.

$O$ delineamento experimental utilizado foi inteiramente casualizado, sendo os resultados submetidos à análise de variância (teste $\mathrm{F}$ ), e as médias comparadas pelo teste de Tukey, ao nível de $5 \%$ de probabilidade. 


\section{RESULTADO E DISCUSSÃO}

Nas Figuras 1, 2 e 3 são apresentados os dados biométricos dos frutos de melão-desão-caetano. A maior parte dos frutos apresenta comprimento em torno de $49-57 \mathrm{~mm}$, diâmetro variando de $17-19 \mathrm{~mm}$ e frutos com aproximadamente 20 a 23 sementes. As variações nas dimensões dos frutos podem ser atribuídas à variabilidade genética, aos fatores ambientais (bióticos e abióticos), bem como a interação genótipo-ambiente. Macedo et al. (2009) verificaram que os frutos de Magonia pubescens têm grande variação nas dimensões e as sementes apresentam menor variação. Quando comparado com outros trabalhos com caracterização biométrica com outras espécies como o de Abud et al. (2009) e Rêgo et al. (2010) encontraram menores variações, em relação aos resultados obtidos com melão-de-são-caetano, nas dimensões dos frutos de Mucuna aterrima e Blepharocalyx salicifolius, respectivamente. Tal fato pode ser atribuído a dificuldade amostral que resultou na análise de apenas 15 frutos (Tabela 1). A amostragem dos frutos foi limitada por estes frutos serem deiscentes, ou seja, abrem quando atingem

TABELA 1. Valores da média, mediana, desvio padrão e variância, referentes à caracterização biométrica de frutos de melão-de-são-caetano (Momordica charantia L.). Mossoró, RN, 2011.

\begin{tabular}{cccc}
\hline Valores & $\mathbf{N}^{\circ}$ de sementes/fruto & Comprimento $(\mathbf{m m})$ & Diâmetro $(\mathbf{m m})$ \\
\hline Média & 17,86 & 49,80 & 19,98 \\
Mediana & 18 & 50,88 & 19,64 \\
Desvio padrão & 5,38 & 8,92 & 3,01 \\
Variância & 28,98 & 79,58 & 9,10 \\
\hline
\end{tabular}

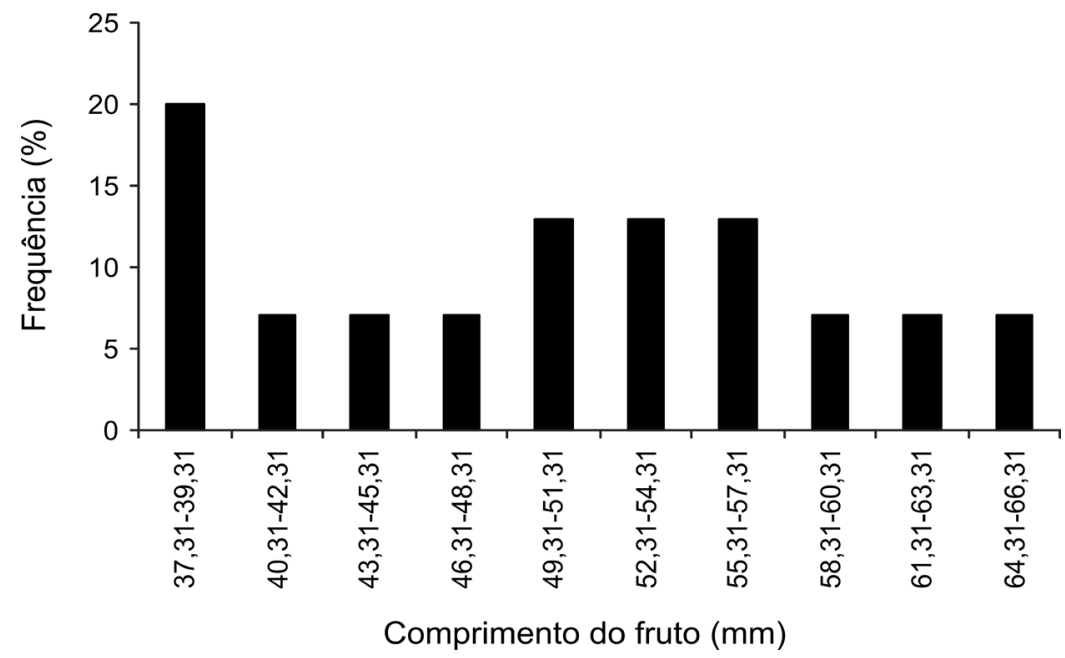

FIGURA 1. Frequência do comprimento do fruto em melão-de-são-caetano (Momordica charantia L.). Mossoró, RN, 2011.

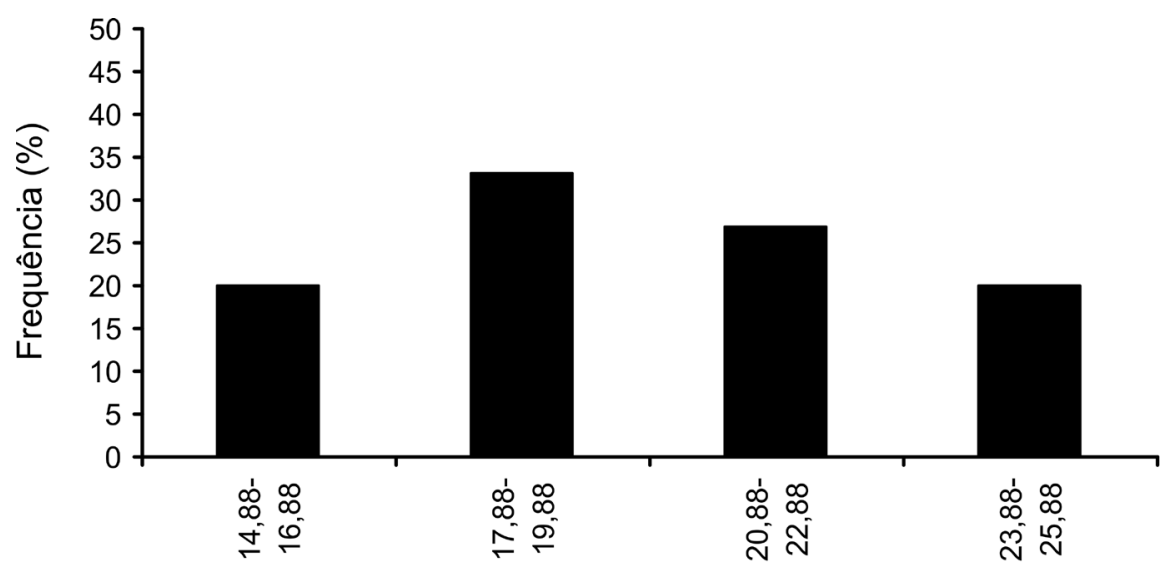

Diâmetro de fruto $(\mathrm{mm})$

FIGURA 2. Frequência do diâmetro do fruto em melão-de-são-caetano (Momordica charantia L.). Mossoró, RN, 2011. 


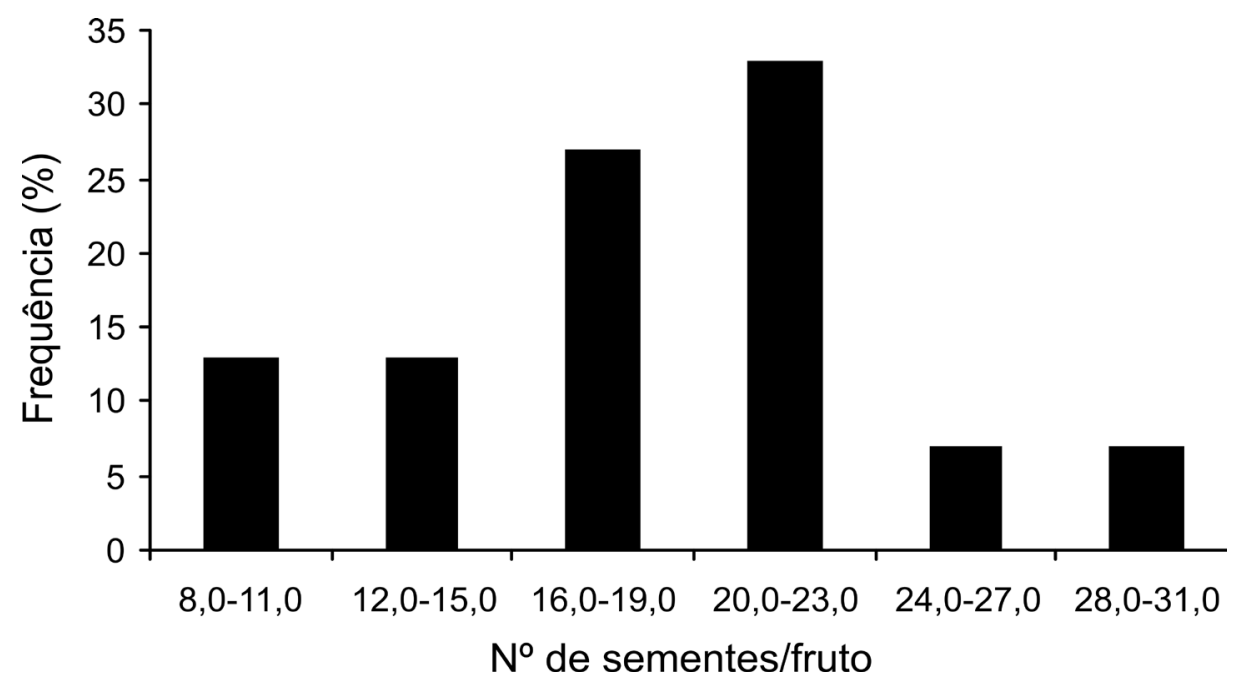

FIGURA 3. Frequência do número de sementes por fruto em melão-de-são-caetano (Momordica charantia L.). Mossoró, RN, 2011.

a maturação.

O teor de umidade das sementes foi de $7,7 \%$. O peso de mil sementes foi de $48,08 \mathrm{~g}$ e o número de sementes por grama foi 21 . Em relação ao tamanho, as sementes apresentaram maior homogeneidade quando comparadas com os frutos
(Tabela 2).

Na região de Mossoró, a maior parte das sementes apresentou comprimento de $7,6-8,5 \mathrm{~mm}$, largura de $4,2-4,4 \mathrm{~mm}$ e espessura de $2,5-2,7 \mathrm{~mm}$, tais resultados podem indicar quais seriam as dimensões das sementes a serem coletadas nesta

TABELA 2. Valores da média, mediana, desvio padrão e variância, referentes à caracterização biométrica de sementes de melão-de-são-caetano (Momordica charantia L.). Mossoró, RN, 2011.

\begin{tabular}{cccc}
\hline Valores & Comprimento $(\mathbf{m m})$ & Largura $(\mathbf{m m})$ & Espessura $(\mathbf{m m})$ \\
\hline Média & 8,09 & 4,29 & 2,65 \\
Mediana & 8,11 & 4,29 & 2,67 \\
Desvio padrão & 0,51 & 0,24 & 0,16 \\
Variância & 0,26 & 0,062 & 0,026 \\
\hline
\end{tabular}

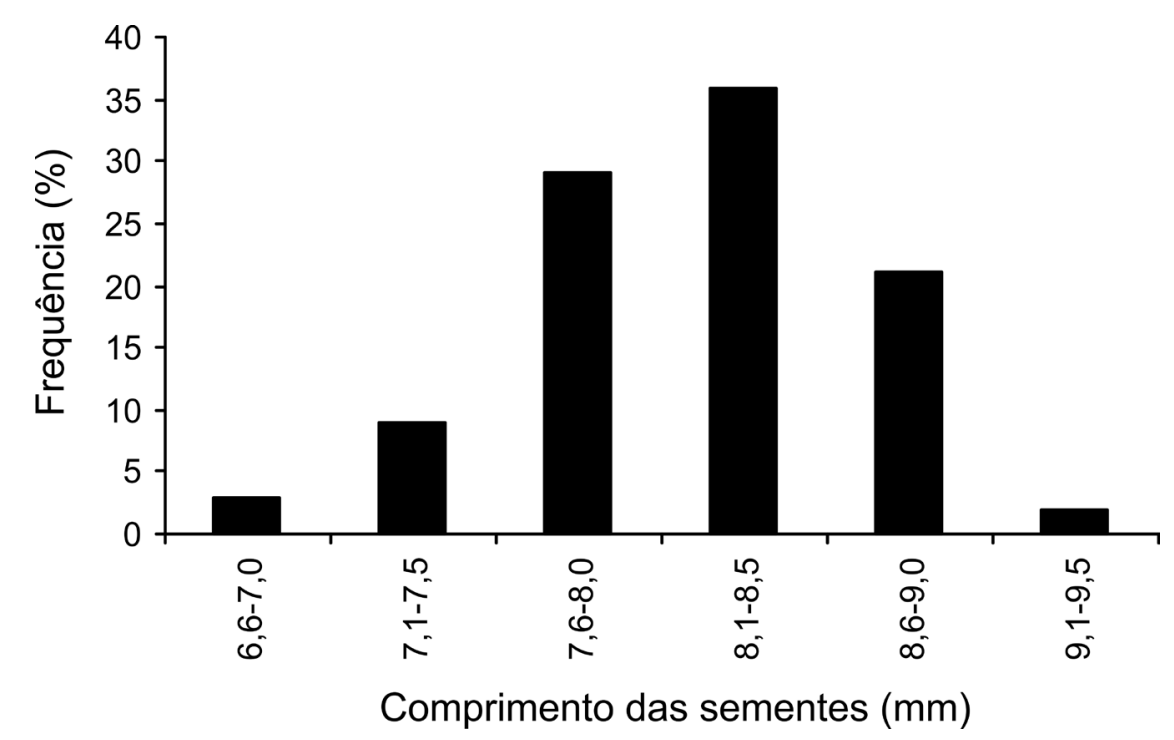

FIGURA 4. Frequência do comprimento de sementes em melão-de-são-caetano (Momordica charantia L.). Mossoró, RN, 2011. 
região. Para Elias et al. (2006), a classificação das sementes pelo tamanho pode ser uma estratégia para conseguir uma germinação rápida e uniforme, diminuindo o período de exposição das sementes as condições adversas.

Houve germinação das sementes entre 20 e $35^{\circ} \mathrm{C}$. Porém, nas temperaturas de 10,15 e $40^{\circ} \mathrm{C}$ não houve germinação. Essas informações concordam, em parte, com as encontradas por Singh (1991) que informa que as sementes de melão-desão-caetano não germinam abaixo de $10^{\circ} \mathrm{C}$ e acima de $50^{\circ} \mathrm{C}$. Para as temperaturas de 10 e $15^{\circ} \mathrm{C}$ não houve morte das sementes, o que foi verificado apenas na temperatura de $40^{\circ} \mathrm{C}$. De acordo com Marcos Filho (2005), a redução gradativa da temperatura provoca decréscimos acentuados na velocidade de germinação, em função dos efeitos sobre a velocidade de mobilização de reservas. Dessa forma, às temperaturas de 20 e $35^{\circ} \mathrm{C}$ foram consideradas, respectivamente, como mínima e máxima para germinação das sementes de melãode-são-caetano. Esta faixa de temperatura está de acordo com a informação de Larkcom (1991), que afirma que as sementes de melão-de-são-caetano apresentam maior percentual de germinação entre $26-29^{\circ} \mathrm{C}$. Resultados semelhantes foram obtidos por Andrade et al. (2000) em sementes de Genipa americana, em que obtiveram maiores porcentagem e velocidade de germinação nas temperaturas constantes de 20,35 e $35^{\circ} \mathrm{C}$ e na temperatura alternada $20-30^{\circ} \mathrm{C}$ (dezesseis horas a $30^{\circ} \mathrm{C}$ e oito horas a $20^{\circ} \mathrm{C}$ ).

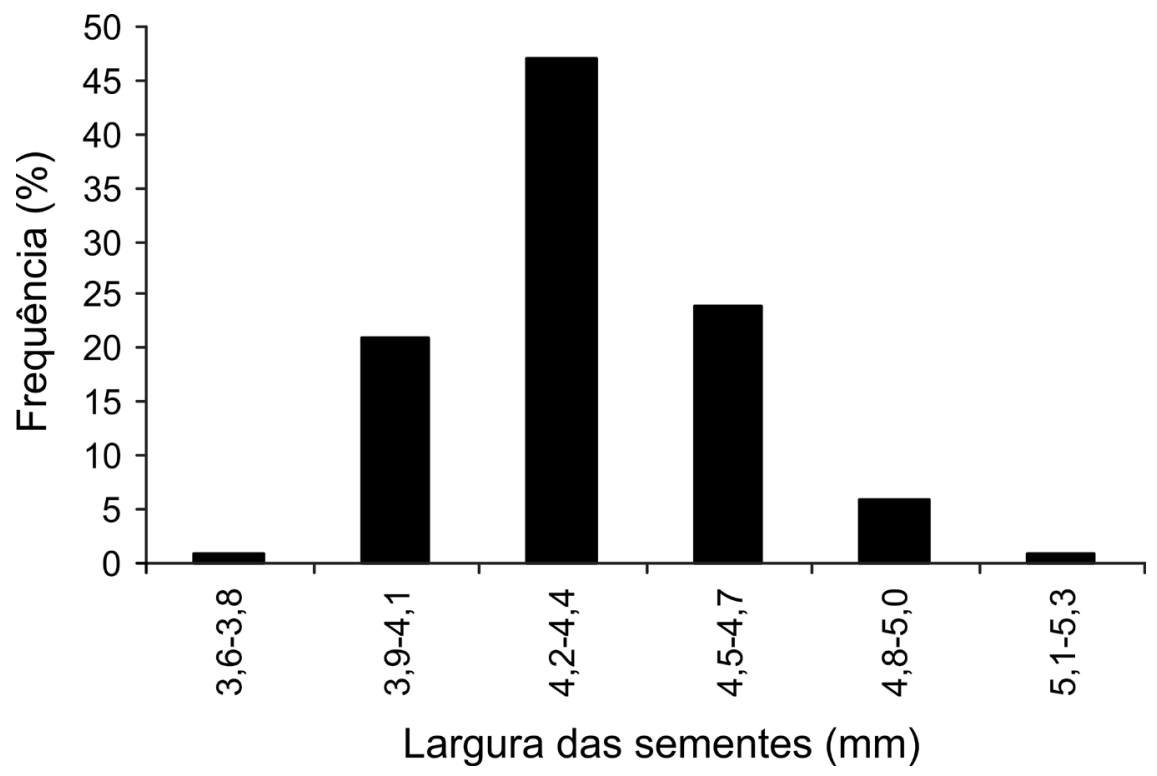

FIGURA 5. Frequência da largura de sementes em melão-de-são-caetano (Momordica charantia L.). Mossoró, RN, 2011.

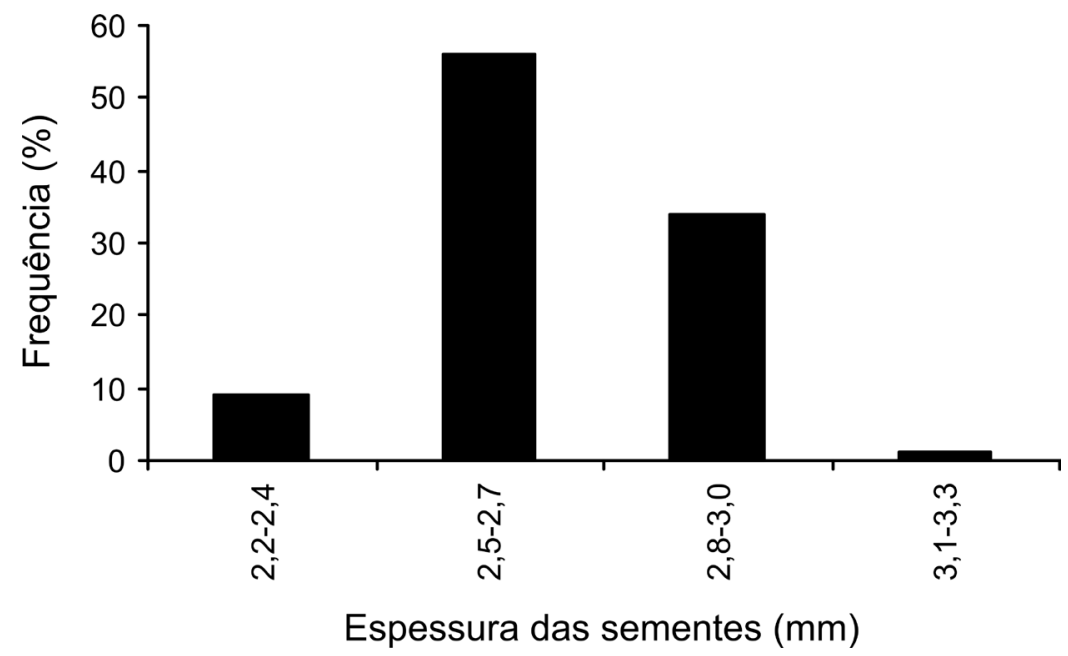

FIGURA 6. Frequência da espessura das sementes de melão-de-são-caetano (Momordica charantia L.). Mossoró, RN, 2011. 
Neste trabalho, os maiores percentuais de germinação (acima de 70\%) e o menor tempo médio de germinação ocorreram entre as temperaturas de 25 e $30^{\circ} \mathrm{C}$. Esta faixa de temperatura $\left(25\right.$ e $\left.30^{\circ} \mathrm{C}\right)$ foi considerada como ótima para germinação das sementes de melão-de-são-caetano. Os resultados obtidos no presente estudo são semelhantes aos obtidos por Alves et al. (2002) que observaram que a temperatura ótima de germinação para maioria das espécies tropicais situa-se entre 15 e $30^{\circ} \mathrm{C}$. Resultados semelhantes também foram obtidos por
Maekawa et al (2010) que verificaram a germinação das sementes de Aristolochia esperanzae na faixa de temperatura de 20 a $35^{\circ} \mathrm{C}$, sendo a temperatura de $30^{\circ} \mathrm{C}$ considerada a mais adequada para o teste de germinação.

Na Figura 7 são apresentadas as curvas de distribuição da germinação de sementes de melãode-são-caetano ao longo do tempo de estudo em cada temperatura, exceto para a de 10,15 e $40^{\circ} \mathrm{C}$, onde não houve germinação. Nas temperaturas de 20,25 e $30^{\circ} \mathrm{C}$, as curvas de frequência apresentaram

TABELA 3. Germinação (\%) e tempo médio de germinação de Momordica charantia L. após incubação isotérmica das sementes em diferentes temperaturas $\left({ }^{\circ} \mathrm{C}\right)$. Mossoró, RN, 2011.

\begin{tabular}{ccc}
\hline Temperatura $\left({ }^{\circ} \mathrm{C}\right)$ & ${\text { Germinação }(\%)^{*}}^{*}$ & Tempo médio de germinação (dia) $^{*}$ \\
\hline 10 & $0 \mathrm{~d}$ & $0,0 \mathrm{c}$ \\
15 & $0 \mathrm{~d}$ & $0,0 \mathrm{c}$ \\
20 & $55 \mathrm{c}$ & $6,7 \mathrm{a}$ \\
25 & $74 \mathrm{a}$ & $4,2 \mathrm{~b}$ \\
30 & $72 \mathrm{ab}$ & $4,0 \mathrm{~b}$ \\
35 & $61 \mathrm{bc}$ & $7,5 \mathrm{a}$ \\
40 & $0 \mathrm{~d}$ & $0,0 \mathrm{c}$ \\
\hline C.V. $(\%)$ & 14,1 & 10,7
\end{tabular}

*Médias seguidas da mesma letra na coluna não diferem entre si pelo teste de Tukey a 5\% de probabilidade.
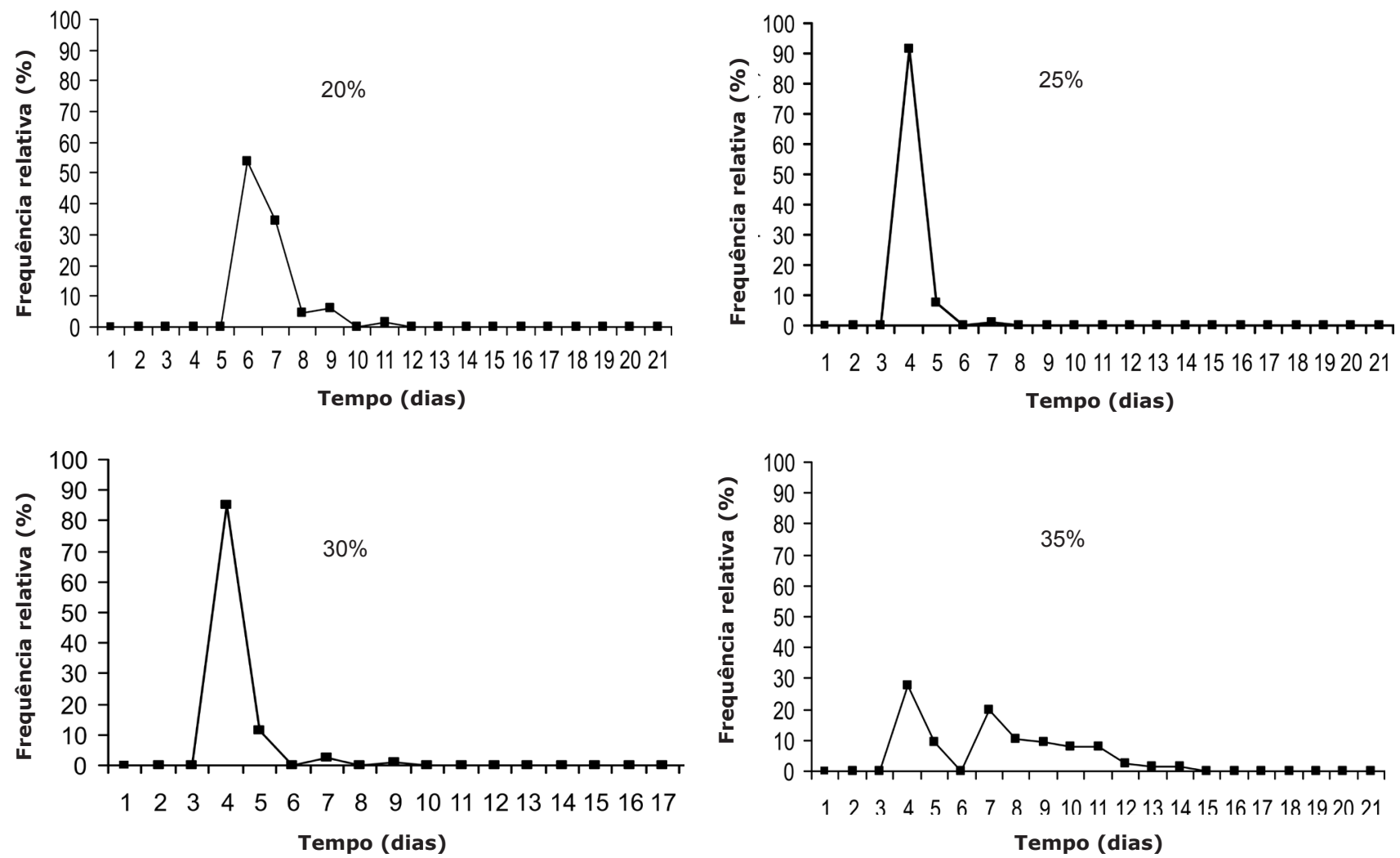

FIGURA 7. Distribuição da frequência relativa da germinação de sementes de Momordica charantia L. em função do tempo de incubação isotérmica em diferentes temperaturas. Mossoró, RN, 2011. 
comportamento assimétrico, já na temperatura de $35^{\circ} \mathrm{C}$ a curva foi do tipo multimodal com mais de dois pontos máximos de germinação.

Nas temperaturas de 25 e $30^{\circ} \mathrm{C}$, o máximo de germinação ocorreu quatro dias após a incubação das sementes, para a temperatura de $20^{\circ} \mathrm{C}$, o máximo de germinação ocorreu entre seis e sete dias; já para a de $35^{\circ} \mathrm{C}$, a distribuição da freqüência apresentou forma irregular, ocorrendo picos de germinação aos quatro, e aos sete dias. Esses resultados divergem dos obtidos por Bezerra et al. (2002), quando utilizaram sementes recém-colhidas de melão-de-são-caetano e verificaram que a germinação máxima ocorreu aos dezessete dias após a semeadura na temperatura de $25^{\circ} \mathrm{C}$ e aos nove dias na temperatura de $25-35^{\circ} \mathrm{C}$.

Diante dos resultados obtidos nesse trabalho, conclui-se que as sementes de melão-desão-caetano, colhidas em Mossoró/RN, apresentam pequena variação nas dimensões; por outro lado, os frutos apresentam dimensões bastante variadas e com grande variação no número de sementes. Verifica-se ampla faixa de temperatura para germinação de sementes dessa espécie, sendo a faixa ótima de $25^{\circ} \mathrm{C}$ a $30^{\circ} \mathrm{C}$; temperaturas acima de $35^{\circ} \mathrm{C}$ e abaixo de $20^{\circ} \mathrm{C}$ são prejudiciais para germinação de sementes de melão-de-são-caetano.

\section{REFERÊNCIA}

ABUD, H. F. et al. Caracterização morfológica de frutos, sementes, plântulas e germinação de Mucuna aterrima Piper \& Tracy. Revista Ciência Agronômica, v.40, n.4, p.563-569, 2009.

ALBUQUERQUE, M.C.F. et al. Germinação de sementes de espécies medicinais do cerrado, In: COELHO, M.F.B. et al. (Org.). Diversos olhares em etnobiologia, etnoecologia e plantas medicinais. Cuiabá: Unicen, 2003. p.157-82.

ALVES, E.U. et al. Germinação e biometria de frutos e sementes de Bauhinia divaricata L. Sitientibus Série Ciências Biológicas, v.7, n.3, p.193-198, 2007.

ALVES, E.U. et al. Germinação de sementes de Mimosa caesalpiniaefolia Benth. em diferentes substratos e temperaturas. Revista Brasileira de Sementes, v.24, n.1, p.169-178, 2002.

ANDRADE, A.C.S. et al. Germinação de sementes de jenipapo: temperatura, substrato e morfologia do desenvolvimento pós-seminal Pesquisa Agropecuária Brasileira, v.33, n.3, p.609-615, 2000.

ARAÚJO NETO, J.C. et al. Caracterização morfológica de frutos e sementes e desenvolvimento pós-seminal de monjoleiro (Acacia polyphylla DC.). Revista Brasileira de Sementes, v.24, n.1, p.203-211, 2002.

ASSUBAIE, N.F.E.; EL-GARAWANY, M.M. Evaluation of Some Important Chemical Constituents of Momordica charantia Cultivated in Hofuf. Journal of Biological Sciences, v.4, p.628-630, 2004.

BEWLEY, J.D.; BLACK, M. Seeds: physiology of development and germination. 2. ed. New York: Plenum Press, 1994. 445p.

BEZERRA, A.M.E. et al. Germinação e desenvolvimento de plântulas de melão-de-são-caetano em diferentes ambientes e substratos Revista Ciência Agronômica, v.33, n.1, p.39-44, 2002.

BRASIL. Ministério da Agricultura, Pecuária e Abastecimento. Regras para análise de sementes. Brasília: Mapa/ACS, 2009. 399p.

CARMO FILHO, F.; OLIVEIRA, O.F. Mossoró: um município do semi-árido nordestino, caracterização climática e aspecto florístico. Mossoró: ESAM, 1995. 62p. (Coleção mossoroense, série $B$ ).

CARVALHO, N.M.; NAKAGAWA, J. Sementes: ciência, tecnologia e produção. 4. ed. Jaboticabal: FUNEP, 2000. 588p.

CRUZ, E.D. et al. Biometria de frutos e sementes e germinação de jatobá-curuba (Hymenaea intermedia Ducke, leguminosae - Caesalpinioideae). Revista Brasileira de Botânica, v.24, n.2, p.161-165, 2001.

ELIAS, M. E. A.; FERREIRA, S. A. N.; GENTIL, D. F. O. Emergência de plântulas de tucumã (Astcaryum aculeatum) em função da posição de semeadura. Acta Amazônica, v. 36, n. 03, p. 385-388, 2006.

FLOSS, E.L. Fisiologia de plantas cultivadas: o estudo que está por trás do que se vê. Passo Fundo: UPF, 2004. 536p.

GROVER, J.K.; YADAV, S.P. Pharmacological actions and potential uses of Momordica charantia: a review. Journal of Ethnopharmacology, v.93, p.123-132, 2004.

GUREVITCH, J. et al. The ecology of plants. Sunderland: Sinauer Associates Inc., 2002. 540p.

LABOURIAU, L.G. A germinação das sementes. Washington: Organização dos Estados Americanos, 1983. 170p. (Monografia, 24).

LARKCOM, J. Oriental vegetables: the complete guide for garden and kitchen. London: John Murray, 1991. 232p.

LORENZI, H. Plantas daninhas do Brasil: terrestres, aquáticas, parasitas e tóxicas. 2. ed. Nova Odessa: Instituto Plantarum, 2008. p. 192-261.

MACEDO, M.C. et al. Biometria de frutos e sementes e germinação de Magonia pubescens ST. Hil (SAPINDACEAE) Revista Brasileira de Sementes, v.31, n.2, p.202-211, 2009.

MAEKAWA, L. et al. Germinação de sementes de Aristolochia esperanzae $\mathrm{O}$. Kuntze em diferentes condições de luminosidade. Revista Brasileira de Plantas Medicinais, v.12, n.1, p.23-30, 2010.

MARCOS FILHO, J. Fisiologia de sementes de plantas cultivadas. Piracicaba: FEALQ, 2005. 495p.

OLIVEIRA, A.N. et al. Estudo morfológico de frutos e sementes de tefrósia (Tephrosia candida DC. PAPILIONOIDEAE) na Amazônia Central. Revista Brasileira de Sementes, v.22, n.2, p.193-199, 2000.

RÊGO, S. S. Caracterização morfológica do fruto, da semente e do desenvolvimento da plântula de Blepharocalyx salicifolius (H.P.K) E Myrceugenia gertii Landrum- Myrtaceae. Revista Brasileira de Sementes, v.32, n.3, p.52-60, 2010.

ROBINSON, R.W.; DECKER-WALTER, D.S. Cucurbits. New York: Cab International, 226p. 1997.

SINGH, D.K. Effect of temperature on seed germinability of Momordica charantia L. cultivars. New Agriculturist, v.2, p.23-26, 1991. 